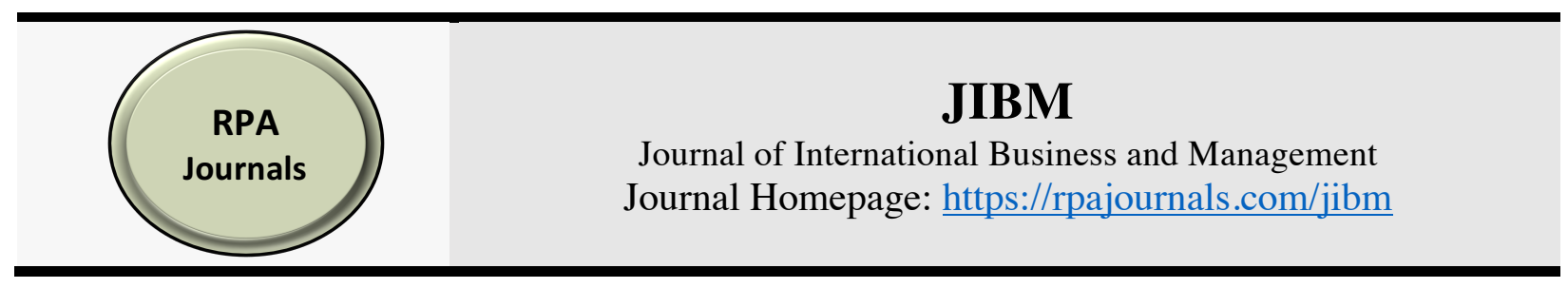

\title{
Factors Influencing the Use of E-wallet as a Payment Method among Malaysian Young Adults
}

\author{
Md Wasiul Karim' \\ Ahasanul Haque*2 \\ Mohammad Arije Ulfy ${ }^{3}$ \\ Md Alamgir Hossain \\ Md Zohurul Anis ${ }^{5}$ \\ Department of Business Administration ${ }^{123 s}$ \\ Graduate School of Management ${ }^{4}$ \\ International Islamic University Malaysia (IIUM), Malaysia ${ }^{123,45}$
}

\begin{abstract}
In recent years, there is a noticeable increase of cashless transactions due to the development of financial technology. As a result of being expansion of fintech products such as e-wallet, consumers are shifting from cash-based to cashless. Young adult consumers in 21 st century are regarded as tech-savvy as they were born in the era of smartphone technology. This study aims to examine the influencing factors for Malaysian young adults to use e-wallet as a payment method by applying extended technology acceptance model (TAM). Total of 330 data were collected from the users of e-wallet in the area of Klang Valley of Malaysia and analyzed by deploying partial least squares structural equation modeling (PLS-SEM). By applying two-step approach for instance, measurement model for indicator loadings, convergent validity, reliability and structural model for path analysis the findings from this study reveal that perceived usefulness, perceived ease of use and privacy and security have positive and significant relationship with behavioral intention to use e-wallet. This study helps the service providers of the digital marketplace further to have better understanding of the usefulness of using e-wallet for transaction purposes.
\end{abstract}

Keywords: Financial Technology, e-wallet, TAM, PLS-SEM, Malaysia.

*Corresponding author Ahasanul Haque E-mail: ahasanul@iium.edu.my

DOI: https://doi.org/10.37227/jibm-2020-2-21

\section{Introduction}

In today world internet has made life easier for people. Payments are being done using smart devices. One of the best inventions of the 21 st century is the electronic wallets (e-wallets) an integral part of electronic payment system. The term "e-wallet" is a form of digital wallet that allows an individual to link their debit or credit cards to digital wallet in order to make any transactions (Digital Wallet , 2019). Apart from the debit or credit cards electronic cards enable consumers to store their physical cards information and bank account number to perform certain action towards payment (Ray, 2017). 
It is pointed out that; payments done using e-wallet is more convenient and faster than conventional banking system as it saves time and money (Blockchains, 2018). The cellular-based payment system is widely being used for transactions and payments are being done through using mobile applications because consumer considers this method to be beneficial (Gokilavani et al., 2018). Payment using ewallet not only provides a level of ease and speed but also gives consumers a sense of comfort and a sense of security in transactions elsewhere and anytime (Liébana-Cabanillas et al., 2014). The use of e-wallet offers small-scale transactions which is very easy to operate (Punwatkar, et al., 2018).

The rapid development of information technology facilitates by providing its distinct characteristics of payment system. Due to the increasing number of e-payment systems, consumers are shifting from cash-based to cashless, yet converting a non-cash economy is difficult, and existing cash-based trading practices are still firmly compacted (Yaokumah, Kumah \& Okai, 2017). However, the growth of e-wallet in Malaysia is mainly due to the several facts one of them are effortless cash transactions followed by security and cost saving (Nizam, Hwang \& Valaei, 2018). Malaysia has more than 42 e-wallets that have received official license from BNM (Bank Negara Malaysia) and among them six are the most popular and widely being used, namely AEON Wallet, Boost, BigPay, GrabPay, WeChat pay and Touch'n Go eWallet. However, these e-wallets play a dominant role in transforming nation towards a cashless future (Oh, 2018).

According to the Erik Eriksons' stage of human development, a young adult is between the ages of 19 and 39, while a teenager is between the ages of 13 and 18. Millennials (Born between 1981 and 1997) and Generation Z (Born from 1997 and onwards) are representing young adults and they are born in the era of new technology (Turner, 2015). In terms of technology Generation Y experienced a major change. The most technological change has been witnessed and globalization has brought them different perceptions and attitudes compared to previous generations (Cobanoglu et al., 2015). Generation $\mathrm{Z}$ grew up with the technology and internet and they are regarded as Igeneration (Mohammed, 2018). As these young generations are currently surfing in the smart technology they desire to experience new applications and its ease of use, security and privacy (Wood, 2013). However, information security and privacy is crucial to think because information violation cases and issues are rising throughout the world like Malaysia (Mohamed, et al., 2012). Lack of knowledge regarding information protection leads a privacy intruder an opportunity to invade someone's privacy i.e. identity theft, credit card fraud and cybercrimes (Barrett-Maitland, Barclay \& Osei-Bryson, 2016).

Technology acceptance model (TAM) was first introduced by Davis (1989), which is adapted from Theory of Reasoned Action (TRA) developed by Fishbein \& Ajzen (1975) and the Theory of Planned Behavior (TPB) by Ajzen (1991), these are particularly well-researched intention models that have proved successful in predicting technology acceptance behavior (Barry and Jan , 2018; Nasri and Charfeddine, 2012). The extended TAM model is including Perceived usefulness (PU), perceived ease of use (PEU), Behavioral intention (BI) and actual system use (ASU).

The main objective of this paper is to investigate factors that influence young adults' to use e-wallet as a payment method. To meet the special objective of this study three variables such as perceived usefulness (PU), perceived ease of use (PEU) and privacy and security (PS) are chosen to see effects on behavioral intention (BI) and actual system use (ASU).The remaining paper exhibits five sections include literature review, research methodology, results and findings and limitation and future research directions.

\section{Literature Review}

\section{Extended Technology Acceptance Model}

Several theories have been developed to understand the intention of the consumer to use an IS technology. TAM model have been studied extensively in several literature (Davis, 1989) and it is in fact the theory of information services that model how users adopt and use a particular technology (Dauda , et al., 2015). Number of researchers have extended the TAM model and applied it to many different technologies including e-learning (Cheung and Vogel, 2013; Al-Maroof and Al-Emran, 
2018), m-commerce (Barry, et al., 2018) and short message service (Muk, et al., 2015). According to Vijayasarathy (2004), TAM variables are best suited for a decision regarding to accept new technology. To study the acceptance and usage intention of new technology, TAM is considered as well-recognized extensions in academic research (Aydin , et al., 2016). However, the original TAM variables may not sufficiently capture core beliefs that affect the attitude of consumers towards eshopping. In order to strengthen the model it is further advised to include few additional variables to examine the appropriateness of the TAM (Jaradat, 2013). Privacy and security is one of the extended variable that was found to be positive on behavioral intention to use new technology (Barry, et al., 2018). Based on the above statements, this study includes privacy and security as one of the extended variables (Barry, et al., 2018) to examine the behavioral intention to use e-wallet. Other two variables are perceived usefulness and perceived ease of use.

\section{E-wallet use}

E-wallet is as an application that allows an individual to make any e-commerce transactions by storing their credit card information. Payment through e-wallet is considered as one of the most prominent transaction method at present because an electronic transaction using a digital wallet has the advantage of ease, flexibility and protection (Uddin, et al., 2014). Mobile wallet is also recognized for its innovative benefits such as customization and instant communication (Osakwe, et al., 2016). As the number of e-payment systems is increasing e-wallet has already gain fame by providing its vast number of services in riding sector, food delivery and bill payments (Rosnidah et al., 2019). It is not only advantageous for buyers; traders are accepting e-wallet as a payment method because of its fastest transaction process, efficient cash management and less cost of labor (Hayashi , et al., 2014). These types of transactions are commonly being done in physical stores where customers scan the $(\mathrm{QR})$ code by using their mobile device to confirm the payment (Lu, 2018). In physical stores, NFC-supported devices (Near Field Communications) are being placed near to the payment terminal to make the transaction easier (Taylor , 2016). Based on the above literature, it can be described that the use of e-wallet among young adults is mainly because of its compatibility, flexibility and user friendly transactions that is done using smart devices.

\section{Behavioral Intention}

Intention can be defined as a course of action that an individual aims to achieve (Zhao, et al., 2010). Behavioral intention is a person's subjective probability that is intended to be attained within a time period (Ajzen , 1988). It refers to the way a person will act in the future (Fishbein, et al., 1975). Ewallet is a new form of payment systems that is widely accepted. In future it is expected to have a great expansion of e-wallet in Malaysia (Nizam et al., 2018). Many scholars found positive and significant relationship between behavioral intention (BI) and new technology use (Barry and Jan , 2018; Faqih and Jaradat , 2015; Jaradat, 2013). According to Mun and Hwang (2003), behavioral intention (BI) has positively and significantly affects actual use (AU). (Venkatesh et al., 2003) Postulates an extended Technology Acceptance Model with four variables; findings from the model reveals that behavioral intention to use has a significant and positive influence on usage behavior. Based on the statements above, the following hypothesis is formed:

H1: Behavioral intention to use e-wallet will have positive influence on e-wallet use.

\section{Perceived Usefulness}

Perceived usefulness refers to a degree to which an individual believes that using a particular information system will lengthen their productivity (Davis, 1989). In TAM framework, perceived usefulness is hypothesized to predict the direct relationship with behavioral intention to use the technology (Park et al., 2014). Perceived usefulness also prescribed as a degree to which a person believes using a particular system will enhance his or her job performance. Perceived usefulness is a strongest factor of TAM that has a significant influence on behavioral intention (Davis, Bagozzi \& Warshaw, 1989). Using TAM model Al-Maroof and Al-Emran (2018) found the significant relationship between perceived usefulness and behavioral intention to use particular technology. 
However, prior studies found to have a positive relationship between perceived usefulness and behavioral intention to use in the context of electronic textbook (Baker-Eveleth and Stone, 2015; Stone and Baker-Eveleth, 2013), cellular service providers (Abbas \& Hamdy, 2015), travel service online (Li \& Liu, 2014) and e-learning (Lin , et al., 2012).

According to Venkatesh et al. (2003) extended TAM model, perceived usefulness found to be significant on behavioral intention and determine one of the strongest factors to predict intention to use particular system. Mun and Hwang (2003) found that, there is a positive and significant relationship between perceived usefulness and behavioral intention. With that abovementioned literature, the following hypothesis is formed:

H2: perceived usefulness of e-wallet will have positive influence on behavioral intention to use ewallet.

\section{Perceived Ease of Use}

The term perceived ease of use signifies to "the extent to which using a particular system will be free from effort" (Davis, 1989). Behavioral intention to use technology is positively and significantly influenced by perceived ease of use (Jackson, Chow \& Leitch, 1997). A study of Venkatesh et al. (2002) reveals that perceived ease of use and behavioral intention to use are positively and significantly associated. Similarly, behavioral intention to use information system is predicted by perceived ease of use (Eze, Ten \& Poong , 2011). The study of Barry and Jan (2018) found positive and significant effect of perceived ease of use on perceived usefulness and perceived use of use on behavioral intention to use particular system. Four longitudinal field of TAM extended by (Venkatesh, et al., 2000) reveals that perceived ease of use is positively influence perceived usefulness and behavioral intention to use. Al-Maroof and Al-Emran (2018) conducted a study on undergraduate students who perceive that using web service technology is easy and user-friendly thus, it has positive influence on perceived usefulness and behavioral intention. Mun and Hwang (2003) posited that there is a significant relationship between perceived ease of use and behavioral intention to use information system. Based on the above statements the following hypothesis id formed:

H3a: perceived ease of use will have positive influence on perceived usefulness of e-wallet.

$\boldsymbol{H} 3 \boldsymbol{b}$ : Perceived ease of use will have positive influence on behavioral intention to use e-wallet.

\section{Privacy and Security}

Privacy is described as an individual's ability to personally monitor self-relevant information (Cliquet et al., 2015). It is an important feature that everyone is aware off. Based on the study of (Soodan , et al., 2020), one of the factors that affect the use of e-wallet is privacy and security which is found to be more suggestive. Lack of security and privacy is one of the issues that keep customers away from purchasing goods unless it is protected (Milberg, Smith \& Bruke, 2000). However, payment through e-wallet without security feature may lead an unauthorized access of personal information and a lucrative opportunity for cybercriminals to breach the data (Kaur et al., 2018).

According to Marimuthu and Roseline (2020) the e-wallet has gain its popularity due to have effortless transactions but still lack of knowledge and awareness among people and fear to make transaction due to have security issues are the major factors that should thought. Customer may not trust the information system provider and they will deny making any transaction through e-payment unless the privacy and security features are involved (Gitau , et al., 2014). Customer with no experience in the field of using technology may have concern regarding security and privacy. Because the rapid increase of technology and its security issues are a matter of serious concern among customer who uses smart technology for transactions. Ahmad et al. (2010) posits that due to the rapid evolution of technology, users have become much more concerned about privacy and security matters and this has contributed to their refusal to disclose their financial information (i.e. debit or credit card details) over internet and e-commerce sites. Based on the abovementioned literature, the following hypothesis is formed:

H4: Privacy and security will have positive influence on behavioral intention to use e-wallet. 


\section{Proposed Model for this Study}

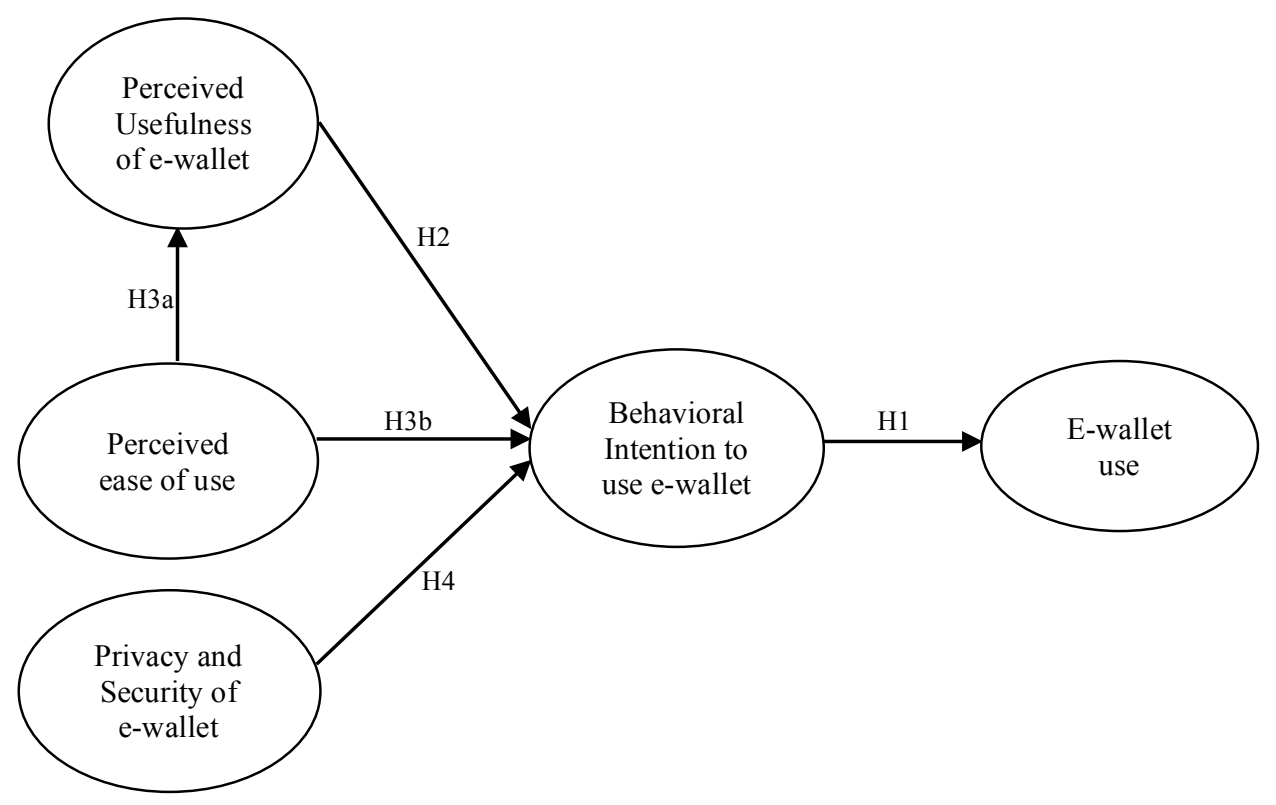

Figure 1: Conceptual Framework

\section{Construct measurement}

\section{Methodology}

The research model comprises five constructs, including perceived usefulness, perceived ease of use, privacy and security behavioral intention to use and e-wallet use. The survey questionnaire for this analysis is formulated on the basis of TAM theory items and adapted mainly from (Barry and Jan, 2018; Davis, Bagozzi and Warshaw, 1989; Sadi and Noordin, 2011). The items from each variable were slightly modified to adjust the current study. All the measurement items were measured using five-point likert scale (i.e. $1=$ strongly disagree to $5=$ strongly agree) to express the statement of agreement.

All the items of the questionnaire were designed using English language only. For the purpose of this study, 30 set of questionnaire were distributed to the university students to conduct a Pilot Study with the aim of getting comments and feedback. The questionnaire was further modified to improve clarity and comprehensibility based on the comments and feedback received from the respondents.

\section{Data Collection}

Data was collected by applying two methods, first is online survey (i.e. sending Google form link to WhatsApp and instant messenger) and second is face-to-face conversation. These data were collected by utilizing throughout the month of January, 2020. The target respondents for this study are to those who have been using e-wallet for long. A total of 330 questionnaires are collected from Klang Valley area in Malaysia. From which only 289 were taken into consideration for data analysis. Rest was omitted as they left the survey form incomplete. 


\section{Data Analysis}

In order to validate the measurement model and structural model this study used Smart PLS software version 3.0.`

\section{Demographic Profile}

The sample illustrates the responses collected from students from Klang Valley which were 330 in total. However, total of 289 valid data were analyzed after removing 41 missing values. Valid responses demonstrate $87.5 \%$ of the total questionnaire distributed. Table 1 shows that total numbers of female respondents were 184 which represent $63.6 \%$ of the total sample while male represents only $36.4 \%$. Moreover, most of the students are aged between 25 and 29 and represents $51.6 \%$ of the total sample followed by aged between 18 and 24 (36.7\%), aged between 30 and $34(7.2 \%)$ and aged between 35 and $39(4.5 \%)$. Furthermore, number of undergraduate students form the survey found to have 218 which explain $75.43 \%$ of the total sample and postgraduate students were 71 in total (24.57\%). Lastly, GrabPay found to have most number of users with 101 and represents $34.94 \%$ followed by Touch'n Go users which explain $30.8 \%$, boost $24.57 \%$, AEON wallet $3.81 \%$, others $3.46 \%$ and WeChat pay $2.42 \%$.

Table 1 Demographic profile

\begin{tabular}{llcc}
\hline Measure & Items & Frequency & Percentage \\
\hline Gender & Male & 105 & 36.4 \\
& Female & 184 & 63.6 \\
\hline Age & $18-24$ & 106 & 36.7 \\
& $25-29$ & 149 & 51.6 \\
& $30-34$ & 21 & 7.2 \\
& $35-39$ & 13 & 4.5 \\
\hline \multirow{2}{*}{ Level of study } & Undergraduate & 218 & 75.43 \\
& Postgraduate & 71 & 24.57 \\
\hline \multirow{2}{*}{ Which e-wallet do you use most? } & AEON Wallet & 11 & 3.81 \\
& Boost & 71 & 24.57 \\
& Touch 'n Go & 89 & 30.8 \\
& GrabPay & 101 & 34.94 \\
& WeChat Pay & 7 & 2.42 \\
& Others & 10 & 3.46 \\
\hline
\end{tabular}

\section{Measurement model}

Convergent and discriminant validity were conducted to assess the measurement model. To evaluate convergent validity, the value of both composite reliability and cronbach's alpha are suggested to be higher than 0.7 (Chin, 1998). Additionally, average variance extracted (AVE) values should be greater than 0.5 as recommended by Hair et al. (2006). Table 2 shows the test results of this study that indicates all the items of the measurement model have good reliability and sufficient convergent validity. The study indicates the value ranging from 0.944 to 0.972 for CR and 0.921 to 0.966 for all cronbach's alphas. The value ranging from 0.809 to 0.892 for average variance extracted (AVE) and outer loadings value for this model is ranging from 0.793 to 0.954 Thus, the test result from the current study can conclude the good reliability of all the items.

To illustrate discriminant validity, it refers the degree to which factors are uncorrelated and distinct (Hair et al., 2013). Measures of different constructs should not correlate highly with each other (Fornell and Larcker, 1981). Table 2 shows the good discriminant validity as it illustrate the square AVE of each factor are larger than any of its correlations with the other factors. 
Table 2: Convergent Validity and Reliability

\begin{tabular}{lcccccccc}
\hline & AVE & CR & $\alpha$ & AU & BI & PEU & PS & PU \\
\hline AU & 0.892 & 0.961 & 0.940 & $\mathbf{0 . 9 4 4}$ & & & & \\
\hline BI & 0.837 & 0.963 & 0.951 & 0.711 & $\mathbf{0 . 9 1 5}$ & & & \\
\hline PEU & 0.857 & 0.960 & 0.944 & 0.617 & 0.616 & $\mathbf{0 . 9 2 6}$ & & \\
\hline PS & 0.809 & 0.944 & 0.921 & 0.572 & 0.679 & 0.591 & $\mathbf{0 . 9 0 0}$ & \\
\hline PU & 0.835 & 0.972 & 0.966 & 0.616 & 0.644 & 0.676 & 0.545 & $\mathbf{0 . 9 1 4}$ \\
\hline
\end{tabular}

\section{Structural model}

The structural model reflects the relationship between the constructs or the latent variables that were hypothesized in this study. Both path coefficients and $\mathrm{R}^{2}$ score were determined by the structural model analysis. According to Hair et al. (2017), $\mathrm{R}^{2}$ values of $0.75,0.50$ and 0.25 which describes substantial, moderate and weak levels of predictive accuracy. The t-value $>1.96$ is significant at $\mathrm{p}<$ 0.05 and $t$-value $>2.58$ is significant at $\mathrm{p}<0.01$ (Hair et al., 2017). So Figure 1 shows the $\mathrm{R}^{2}$ value in this model is $45.6 \%$ for PU, $57.5 \%$ for BI and $50.4 \%$ for AU.

Figure 1 and table 3 illustrates the path coefficient $(\beta), t$-statistics and $p$-value of each hypothesis. Based on the analysis all the hypotheses are found to be significant thus supported. $\mathrm{HI}$ $(\beta=0.711, t=13.917)$ indicates the path between behavioral intention to use e-wallet and actual use; describing the positive and significant relationship among BI and AU of e-wallet. $H 2(\beta=0.308, \mathrm{t}=$ 4.461) shows the path between perceived usefulness and behavioral intention; representing positive relationship between PU and BI to use e-wallet. $H 3 a(\beta=0.676, \mathrm{t}=14.774)$ demonstrates the positive relationship between perceived ease of use and perceived usefulness of e-wallet. $H 3 b(\beta=0.162$, $\mathrm{t}=$ 0.018 ) explains that perceived ease of use have positive and significant influence on behavioral intention to use e-wallet. Lastly $H 4(\beta=0.415, \mathrm{t}=5.677)$ demonstrates that, positive and significant relationship is associated between perceived security and behavioral intention to use e-wallet.

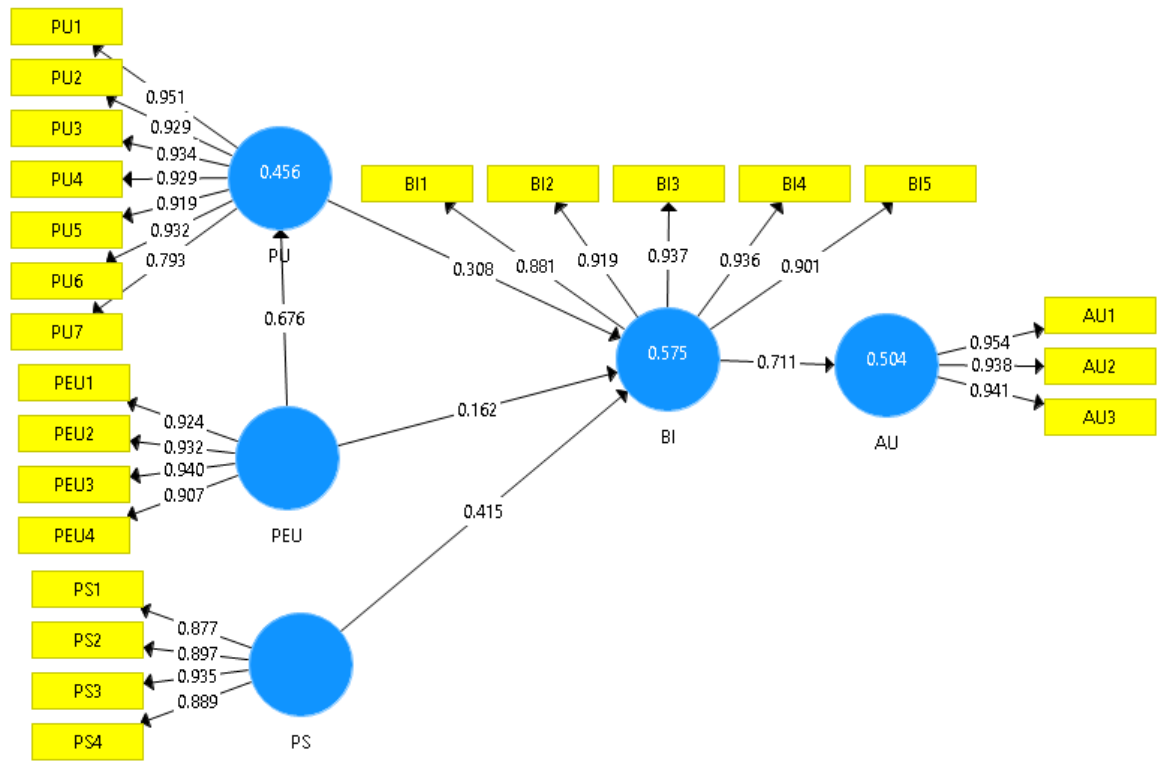

Figure 2: Path analysis, outer loadings and R Squared

\section{Discussion}

This study aims to explore e-wallet usage intention among Malaysian young adults by applying technology acceptance model. The study also examined behavioral intention and its influence on 
actual use. The role of perceived usefulness, perceived ease of use and privacy are also key determinant to examine the behavioral intention to use e-wallet.

Study found behavioral intention to be significant influence on actual use of e-wallet thus, current study is in line with the findings of (Barry and Jan, 2018; Venkatesh, Speier and Morris, 2002; Al-Maroof and Al-Emran, 2018; Davis, 1989). PU have significant influence on BI because, the use of e-wallet saves time and it is convenient in order to make any payment thus, findings from this study is in line with the prior study of (Baker-Eveleth, et al., 2015). However, PEU found to be positive and significant influence on PU and BI, and indicating strong relationship among PEU and PU. The easier an e-wallet is to use, the more useful it can be thus, result is consistent with the previous study by (Venkatesh, et al., 2000). So it is important for e-wallet providers to bear in mind that applications which are easy to use may have positive impact on consumers' behavioral intention to use. Privacy and security found to have positive relationship with behavioral intention. Less privacy and security may lead consumer feel unprotected to use e-wallet application for transactions (Barry, et al., 2018).

Table 3: Results of Proposed Model

\begin{tabular}{cccccc}
\hline Hypotheses & Path & $\boldsymbol{\beta}$ & T-stats & $\boldsymbol{p}$-Value & Decision \\
\hline $\mathrm{H} 1$ & $\mathrm{BI} \rightarrow \mathrm{AU}$ & 0.711 & 13.917 & 0.000 & Supported \\
\hline $\mathrm{H} 2$ & $\mathrm{PU} \rightarrow \mathrm{BI}$ & 0.308 & 4.461 & 0.000 & Supported \\
\hline $\mathrm{H} 3 \mathrm{a}$ & $\mathrm{PEU} \rightarrow \mathrm{PU}$ & 0.676 & 14.771 & 0.000 & Supported \\
\hline $\mathrm{H} 3 \mathrm{~b}$ & $\mathrm{PEU} \rightarrow \mathrm{BI}$ & 0.162 & 2.365 & 0.018 & Supported \\
\hline $\mathrm{H} 4$ & $\mathrm{PS} \rightarrow \mathrm{BI}$ & 0.415 & 5.677 & 0.000 & Supported \\
\hline
\end{tabular}

\section{Conclusion and Future Direction}

It should be noted that this analysis has few limitations. Firstly, due to a finite time of researcher, this study focused on students pursuing university degrees in Klang Valley which may not best representing Malaysia. As the usage of digital payment system has widely being expanded it is further suggested that the study should be executed throughout Malaysia including rural and urban areas. Secondly, young adults are not only pursuing their degrees in different universities they are also being employed in different job sectors and institutions. The decision of using e-wallet however may vary based on different income scales of young adults.

This study was conducted to see the behavior among young adults regarding an intention to use e-wallet. Perceived usefulness, perceived ease of use and behavioral intention are previously used to determine the actual usage behavior. As privacy and security become a major concern among young generations for using digital technology, this study employed privacy and security variable to examine the effects on behavioral change. Privacy and security is one of the prerequisite dimensions that e-wallet providers should emphasize in order to create a positive intention among consumers. Without proper protection of privacy and security customers will be cautious about using e-wallet technology (Wei et al., 2009).

It is suggested further to include few more variables to examine the usage intention of electronic wallet. Distinct features such as trust, cost, and reliability are recommended further to apply in the study on behavioral intention to use electronic wallet. So the future study can be replicated by using the same concept but different context to study the behavioral intention to use ewallet.

\section{References}

Abbas , H. A., \& Hamdy , H. I. (2015). Determinants of continuance intention factor in Kuwait communication market: Case study of Zain-Kuwait. Computers in Human Behavior, 49, 648-657. 
Ahmad , K., Khan , M. I., \& Jan , M. T. (2010). Online Banking Acceptance in Malaysia: A Students' Behaviour Perspective. Malaysian Management Review, 45(2), 1-14.

Ajzen , I. (1988). Attitudes, personality, and behavior. McGraw-Hill Education (UK).

Al-Maroof, R. S., \& Al-Emran , M. (2018). Students acceptance of Google classroom: An exploratory study using PLS-SEM approach. International Journal of Emerging Technologies in Learning, 13(6), 112-123.

Aydin , G., \& Burnaz, S. (2016). Adoption of Mobile Payment Systems: A Study on Mobile Wallet. Journal of Business, Economics and Finance, 5(1), 73-92.

Baker-Eveleth , L., \& Stone , R. W. (2015). Usability, expectation, confirmation, and continuance intentions to use electronic textbooks. Behaviour \& Information Technology, 34(10), 9921004.

Barrett-Maitland, N., Barclay, C., \& Osei-Bryson, K. M. (2016). Security in social networking services: a value-focused thinking exploration in understanding users' privacy and security concerns. Information Technology for Development 22(3), 464-486.

Barry , M., \& Jan , M. T. (2018). Barry, M., \& Jan, M. T. (2018). Factors Influencing the Use of MCommerce: An Extended Technology Acceptance Model Perspective. International Journal of Economics, Management and Accounting, 26(1), 157-183.

Blockchains. (2018, February 1). Growing use of digital wallets [Summary of studies by country]. Retrieved February 13, 2020, from http://bcmy.io/blog/growing-use-of-digital-walletssummary-of-studies-by-country/

Cheung , R., \& Vogel , D. (2013). Predicting user acceptance of collaborative technologies: An extension of the technology acceptance model for e-learning. Computers \& education, 63, $160-175$.

Chin , W. W. (1998). The partial least squares approach to structural equation modeling. Modern methods for business research, 295(2), 295-336.

Cliquet, G., Gonzalez, C., Huré, E., \& Picot-Coupey, K. (2015). From Mobile Phone to Smartphone: What's New About M-Shopping? Ideas in Marketing: Finding the New and Polishing the Old (pp. 199-202). Springer, Cham.

Cobanoglu, C., Yang , W., Shatskikh , A., \& Agarwal , A. (2015). "Are consumers ready for mobilepayment? An examination of consumer acceptance of mobile payment technology in restaurant industry". Hospitality Review, 31(4), 1-18.

Dauda , S. Y., \& Lee, J. (2015). Technology adoption: A conjoint analysis of consumers' preference on future online banking services. Information Systems, 53, 1-15.

Davis , F. D., Bagozzi , R. P., \& Warshaw, P. R. (1989). User acceptance of computer technology: a comparison of two theoretical models. Management science, 35(8), 982-1003.

Davis, F. D. (1989). Perceived Usefulness, Perceived Ease of Use, and User Acceptanceof Information Technology. MIS Quarterly, 13(3), 319-340.

Digital Wallet . (2019, February 13). Retrieved from Wikipedia: https://en.wikipedia.org/wiki/Digital_wallet

Erikson, E. H., \& Van Tassel , D. D. (1976). Aging, death and the completion of being.

Eze, U., Ten, M., \& Poong, Y. (2011). Mobile commerce usage in Malaysia. International conference on social science and humanity, (pp. 265-269).

Faqih , K. M., \& Jaradat, M. (2015). Assessing the Moderating Effect of Gender Differences and Individualism-Collectivism at Individual-Level on the Adoption of M-commerce Technology: TAM3 Perspective. Journal of Retailing and Consumer Services, 22, 37-52.

Fishbein, M., \& Ajzen , I. (1975). Belief, attitude. Intention and Behavior: An Introduction to Theory and Research.

Gitau , L., \& Nzuki , D. (2014). Analysis of determinants of m-commerce adoption by online consumers. International Journal of Business, Humanities and Technology, 4(3), 88-94.

Gokilavani , R., Kumar, D. V., Durgarani , M., \& Mahalakhsmi , R. (2018). Can India Move Towards Digital Sovereign Currency ? A Study on Perception of Consumers Towards. International Journal of Pure and Applied Mathematics, 119(17), 2167-2175. 
Hayashi ,F., \& Bradford, T. (2014). Mobile payments: Merchants' perspectives. Economic Review, 99, 5-30.

Jackson , C. M., Chow , S., \& Leitch , R. A. (1997). Toward an Understanding of the Behavioural Intention to Use an Information System. Decision Sciences 28(2), 357-389.

Jaradat , M. (2013). Applying the Technology Acceptance Model to the Introduction of Mobile Voting. International Journal of Mobile Learning and Organisation 7(1), 29-47.

Jaradat , M. R. (2013). Applying the Technology Acceptance Model to the Introduction of Mobile Voting. International Journal of Mobile Learning and Organisation, 7(1), 29-47.

Kaur , R., Li, Y., Iqbal , J., Gonzalez, H., \& Stakhanova, N. (2018, July ). A Security Assessment of HCE-NFC Enabled E-Wallet Banking Android Apps. 2018 IEEE 42nd Annual Computer Software and Applications Conference (COMPSAC) (pp. 492-497). IEEE.

Lee, M. K., Cheung , C. M., \& Chen , Z. (2005). Acceptance of Internet-Based Learning Medium: The Role of Extrinsic and Intrinsic Motivation. Information and Management 42(8), 10951104.

Li, H., \& Liu , Y. (2014). Understanding post-adoption behaviors of e-service users in the context of online travel services. Information \& Management, 51(8), 1043-1052.

Liébana-Cabanillas, F. J., Sánchez-Fernández, J., \& Muñoz-Leiva, F. (2014). Role of Gender on Acceptance of Mobile Payment. Industrial Management \& Data Systems, 114(2), 220-240.

Lin , W. S., \& Wang , C. H. (2012). Antecedences to continued intentions of adopting e-learning system in blended learning instruction: A contingency framework based on models of information system success and task-technology fit. Computers \& Education, 58(1), 88-99.

Lu, L. (2018). Decoding alipay: mobile payments, a cashless society and regulatory challenges. Butterworths Journal of International Banking and Financial Law, 33(1), 40-48.

Marimuthu , M., \& Roseline, A. (2020). A Study On Consumer Perception Towards E-Wallet. Our Heritage, 68(17), 283-288.

Milberg, S. J., Smith , H. J., \& Bruke , S. J. (2000). Information privacy: Corporate management and national regulation. Organization science, 11(1), 35-57.

Mohamed, N., \& Ahmad, I. H. (2012). Information privacy concerns, antecedents and privacy measure use in social networking sites: Evidence from Malaysia. Computers in Human Behavior, 28(6), 2366-2375.

Mohammed , A. B. (2018). Selling smartphones to generation Z: understanding factors influencing the purchasing intention of smartphone. International Journal of Applied Engineering Research, 13(6), 3220-3227.

Muk, A., \& Chung, C. (2015). Applying the technology acceptance model in a two-country study of SMS advertising. Journal of Business Research, 68(1), 1-16.

Mun, Y. Y., \& Hwang , Y. (2003). Predicting the Use of Web-based Information Systems: Selfefficacy, Enjoyment, Learning Goal Orientation, and the Technology Acceptance Model. International Journal of Human-Computer Studies, 59(4), 431-449.

Nasri, W., \& Charfeddine, L. (2012). Factors affecting the adoption of Internet banking in Tunisia: An integration theory of acceptance model and theory of planned behavior. The Journal of High Technology Management Research, 23(1), 1-14.

Nizam , F., Hwang , H. J., \& Valaei, N. (2018, July ). Measuring the Effectiveness of E-Wallet in Malaysia. 3rd IEEE/ACIS International Conference on Big Data, Cloud Computing, and Data Science Engineering (pp. 59-69). Springer, Cham.

Oh, A. (2018, December 12). The e-wallet infinity war in Malaysia-Everything you need to know about e-wallet starts here. Retrieved February 14, 2020, from ecinsider: https://www.ecinsider.my/2018/12/malaysia-ewallet-battle-landscape-analysis.html

Osakwe, C. N., \& Okeke, T.C. (2016). Facilitating mCommerce growth in Nigeria through mMoney usage: A preliminary analysis. Interdisciplinary Journal of Information, Knowledge, and Management,11, 115-139. 
Park , N., Rhoads, M., Hou, J., \& Lee, K. M. (2014). Understanding the acceptance of teleconferencing systems among employees: An extension of the technology acceptance model. Computers in Human Behavior, 39, 118-127.

Punwatkar, S., \& Verghese, M. (2018). Adaptation of e-Wallet Payment: An Empirical Study on Consumers' Adoption Behavior in Central India. International Journal of Advanced in Management, Technology and Engineering Sciences, 1147-1156.

Ray , A. (2017, November 8). What are the different types of e-commerce payment systems? Retrieved February 13, 2020, from Amazon Services: https://services.amazon.in/resources/seller-blog/different-types-of-e-commerce-paymentsystems.html

Rosnidah , I., Muna , A., Musyaffi ,A. M., \& Siregar , N. F. (2019, March ). Critical factor of mobile payment acceptance in millenial generation: Study on the UTAUT model. International Symposium on Social Sciences, Education, and Humanities (ISSEH 2018). Atlantis Press.

Sadi, A., \& Noordin , M. F. (2011, January ). Factors influencing the adoption of M-commerce: An exploratory Analysis. An exploratory Analysis. In International Conference on Industrial Engineering and Operations Management, (pp. 492-498).

Soodan , V., \& Rana, A. (2020). Modeling Customers' Intention to Use E-Wallet in a Developing Nation: Extending UTAUT2 With Security, Privacy and Savings. Journal of Electronic Commerce in Organizations, 18(1), 89-114.

Stone , R. W., \& Baker-Eveleth , L. (2013). Students' expectation, confirmation, and continuance intention to use electronic textbooks. Computers in Human Behavior, 29(3), 984-990.

Taylor, E. (2016). Mobile payment technologies in retail: A review of potential benefits and risks. International Journal of Retail \& Distribution Management, 44(2), 159-177.

Turner, A. (2015). Generation Z: technology and social interest. The Journal of Individual Psychology, 71(2), 103-113.

Uddin , M. S., \& Akhi , A. Y. (2014). E-wallet system for Bangladesh an electronic payment system. International Journal of Modeling and Optimization, 4(3), 216-226.

Venkatesh , V., Morris , M., Davis , G., \& Davis, F. (2003). User acceptance of information technology: toward a unified view. MIS Quarterly, 27(3), 425-478.

Venkatesh , V., Speier, C., \& Morris , M. G. (2002). User acceptance enablers in individual decision making about technology: Toward an integrated model. Decision sciences, 33(2), 297-316.

Venkatesh, V., \& Davis, F. D. (2000). A theoretical extension of the technology acceptance model: Four longitudinal field studies. Management science, 46(2), 186-204.

Vijayasarathy, L. R. (2004). Predicting Consumer Intentions to Use On-Line Shopping: The Case For an Augmented Technology Acceptance Model. Information and Management 41(6), 747-762.

Wei , T. T., Marthandan , G., Chong , A. Y., Ooi, K. B., \& Arumugam , S. (2009). What drives Malaysian m-commerce adoption? An empirical analysis. Industrial management \& data systems, 109(3), 370-388.

Wood , S. (2013). Generation Z as consumers: trends and innovation. Institute for Emerging Issues: NC State University, 1-3.

Yaokumah , W., Kumah , P., \& Okai , E. A. (2017). Demographic influences on e-payment services. Journal of E-Business Research, 13(1), 44-65.

Zhao, W., \& Othman , M. N. (2010). Predicting and Explaining Complaint Intention and Behavior of Malaysian Consumers: An Application of The Planned Behavior Theory. Advances in International Marketing, 9(1), 229-252. 